\title{
Systematic Approach to A New Service Ideas Conceptualisation: Quantitative Decision Making
}

\author{
Egle Drejeriene ${ }^{1}$, Rolandas Drejeris ${ }^{2}$
}

${ }^{1}$ Lithuanian University of Health Sciences

A. Mickeviciaus st. 9, LT 44307 Kaunas, Lithuania

E-mail.edrejeriene@gmail.com

${ }^{2}$ Vilnius Gediminas Technical University

Sauletekio av. 11, Vilnius, Lithuania

and

A. Stulginskis University

Studentu st. 11; LT-53361 Academy, Kauno reg., Lithuania

E-mail.rdrejeris@gmail.com

cross $^{\text {ref }}$ http://dx.doi.org/10.5755/j01.ee.28.3.14752

Contradictory opinions about some stages in a new service development cause many uncertainties, especially when transferring actions of theoretical implementation into practice. Such ambiguities are particularly typical for the process of conception formation, also evaluation and service system creation. The aim of the paper is to provide a justified model of new service concept(s) formation, its assessment and service system (new service technology) designing. Because of the lack of data about service concept formation, reference was also made to the sources of information about product concept creation. Scientific information on the issues of concept formation was analysed (systematised, structured and synthesised basing on sparse works of other authors) after being assessed in terms of logic and integrity, availability and practical appropriateness for service business. Research findings are used to develop a process model. It consists of the following main components: determining the purposefulness of new service development, concepts designing, concepts assessment according to two different sets of criteria, decision making about service system designing (new service technology designing). Application of the proposed model will show a real ways for the formation of new service concepts. Flexible construction of the model allows reducing time needed for the evaluation and implementation a new service.

Keywords: New Service, Concept, Process Model, Actions, Designing.

\section{Introduction}

Scientific literature suggests a lot of different methodologies for a new service (NS) implementation, but most of them are quite contradictory in terms of both the suggested sequence of the stages and even their content. Particularly many contradictions are found in the new service concept development area. Therefore, the object of this research is the processes of new service ideas conceptualization. Some researches in their works even prefer to skip the stages of concept creation and also concept assessment only in order to shorten NS implementation process, without any verification of such choices. On the contrary, other researchers acknowledge the necessity of concepts formation step in the schemes (models) of new product development. However, any appropriate methodology for the performance of these processes has not been provided yet. So, the situation remains unclear, whether this stage is necessary at all and what actions, if any, are required.

The mentioned contradictions, as well as the lack of clear systematic decisions constitute a problem, which is relevant to science and especially to business. Such circumstances caused the requirements for a more detailed analysis of authors' scientific positions and arguments in order to ascertain the need for the new service concept creation stage, and necessity of concepts assessment and also service system designing steps. So, the aim of this paper is to provide a reasoned process model of new service concept(s) formation and service system (new service technology) designing. Due to the lack of data about service concept formation, other kinds of scientific literature on product concept creation was also reviewed. Scientific information on the issues of concept formation is analysed (systematised and synthesised in accordance with classical rules) on the basis of sparse works of various authors and assessed for its logic and integrity, availability and practical appropriateness for service business. The results of the analysis are used to create the process model and its suitability is tested in real healthcare business conditions.

In 2015, we were included into a project with some Health care organizations and pharmacies of the Republic of Lithuania for the organisation of a new service (implementation of e-prescriptions). Project participants conducted surveys of pharmacy customers, interacted with IT firms and drew valid conclusions on the basis of the research findings. 


\section{A Methodological Aspect of New Service Conceptualisation}

Lee et al. (2010) have found a lack of comprehensive research about processes between idea generation and launch. Service firms in practice mostly use informal procedures in the process of NS ideas and concepts designing and their assessment, because managers often cannot discover differences between these categories. So, what is the essence of a new service concept? According to Bator and Bator (2010), product concept may be considered as detailed version of any new product idea stated in appropriate forms for clients.

A need for the new service concept formation is rationalised by the evidence of Zeithaml et al. (2009). Their work has explained that an idea simply may imprecisely describe only new service basic outline, which implementation should be directed to better meet requirements of specific consumers. Ulrich \& Eppinger (2008) suggest an explanation that a product (or service) concept should be only approximate description of the technology producing, working principles and may define form of the product (or service providing). According to Konu et al. (2010), for the service company staff a new service concept might mean not only the determination but also a more specific definition of the procedures' circuit in the customers servicing processes. It is a short description of some service product possibility to satisfy a customer's needs. A concept usually can be expressed as even a sketch or as a rough three-dimensional pattern and it is often accompanied by brief textual description (Konu et al., 2010). Ulrick \& Eppinger (2008) state that conception means ideas purification to the point at which a service blueprint represents the implementation plan. Blueprint designates all the expressions of the relationship between service providers with service users.

Hence, a new service concept can be expressed in many ways. And which of them is the best? One way is to express it verbally by while showing how the artefact would work using gestures and physical objects (Ulrick \& Eppinger, 2008). Other ways can vary depending on the equipment used, specific place and others attributes. Even He et al. (2015) argues that different conceptual solutions can give different added value for a service company. Some researchers try to discuss this from a particular point of view: how does the concretisation of ideas occur and what role does the physical space (Henrich et al., 2015). Investigators proposed many models but, in summary, concept might concretise ideas by these characteristics:

- Content of service;

- Type of material used;

- Devices or equipment used;

- Time for service providing (or particular operations);

- Time for service preparing;

- Service space;

- Amount of energy used;

- Forces of service provider;

- Results (benefit) for the consumers;

- Place of providing service;

- Better quality of new service;

- Customer involvement.
Discussions with service company clients about the ways of presenting concepts may open up some opportunities to adjust and possibilities to improve the concepts of new service in order to better adapt them to the requirements of some specific segment of the consumers (Gomes et al., 2007; Zomerdijk \& Voss, 2011).

\section{Requirements for the Model of New Services Concept Formation}

It should be noted that some authors have controversial minds about the sequence of the steps for concepts development. Several of them even omit the steps of concepts formation and assessment and such situation is as a result of possible failure to reach a real consensus about the necessity thereof because of even various explanation of the consistency of the following processes.

The scheme for new products development is presented in the Tidd \& Bodley (2002) research, in their model the first component is concept formation, while concepts evaluation actions are offered as the next (or second) stage. It should be stated that such an attitude can bring some kind of confusion to a harmony of the processes, because the more equitable and systematically reasoned approach is that conceptions have to be built on the basis of created new ideas, while a designing of new ideas is not even remembered by mentioned researchers. But Wood (2003) supports the deeply systematic attitudes of implementation of any innovations. According to him it is better to skip the stages of concepts formation and also assessment, because of a new product is developed on the basis of already selected and verified ideas that have been already adopted earlier as really appropriate and useful for the company commercial activity. Incidentally, Wood (2003) and some other authors highlights the responsibility and importance of an idea assessment (and selection) stage, because the results of assessment may be as a basis for making one of the most important commercial decisions about new product (service) implementation. However, the concept assessment stage is really necessary, though it obviously may be simplified in some cases and in different situations. We refer to a proposal by Chenet et al. (2010) to differentiate valued services before assessment. So, we can differentiate new services concepts. Such a proposal even better meets Chenet et al. (2010) approach. For example, concepts assessment of technologically and technically straightforward (uncomplicated) services even can be segregated due to some special features of services, mentioned by many researches (i.e., inseparability, intangibility and perishability). Such as a staging new copy machine in students hostel is treated as a new uncomplicated service. So, if the ideas assessment stage is omitted, it is quite possible situation that prepared concepts will be formed on the basis of even wrong and therefore inappropriate ideas. Moreover, any a possible and suitable idea can be also implemented in different ways. In this respect, the costs of inappropriate concept formation are really worthless. In order to escape any useless outlay, assessment and selection of ideas we suggest at the one of the initial stages of new service development. In that case concepts should be formed only on the basis of screened and evaluated ideas that have been earlier accepted for 
implementation. Accordingly, we can accept Wood's (2003) arguments about the strict organizing of screening and also selection procedures and can agree by systematically approach that not every concepts require to assess, but this can only be valid for ideas, which concepts require only minor modifications of existing services, and for which are widely known to an undertaking managers and/or consumers or perhaps do not require high costs of development.

Also, it is worth to state that many researchers are seen as quite similar processes of concept assessment and analysis of business conditions and sometimes make no difference between them. For example, Thirugnanam et al. (2007) denote that concept assessment and selection stage indicates a process testing of commercial feasibility in accordance with a current business conditions, i.e., these both mentioned processes are determined, but are not distinguished in the their proposed model. Likewise, Thirugnanam et al. (2007) ensure that commercial feasibility of new service conceptions can be determined by their presenting to a market with describing also the main features of NS and verification of the possible clients' reaction (degree of recognition) and their satisfaction. So, the criteria for concept assessment have been connected with economic (commercial) feasibility and potential profit implications.

Service concepts development process being so closely related to the operational system of the service organisation, and according to Lee at al. (2010) this separated step of NS implementation must involve preliminary assumptions about the costs of service employees hiring and training, delivery system enhancements, possible facility changes, and any other projected operations costs.

A new service often occurs based on existing services. In such a situation, a natural starting point for concept formation work is to analyse the existing services in detail. Customers' participation in the process of service providing also must be analysed, though customers sometimes feel as sacrifices (Olsen \& Sallis, 2006). Therefore, all the existing service participants have to be the objects of this analysis, which results will show a true picture of customers' needs. Service providers will get a clear picture of customers' opinions about the existing services and the areas which also need to improve.

Improvement is less risky in such cases, comparing with the risk of creating quite new services (Thirugnanam et al., 2007). When it is obvious that users exactly need only improved service, a detailed assessment of new service concepts is not required then.

Methodology for new service concept assessment at first has to be simple and clear, not requiring much expenditure to understand and high level of education. Nowadays, governments especially encourage entrepreneurship among individuals and provide a variety of privileges for business pioneers, even those who do not yet have any business experience. Practices show that development of new services is the most common activity for business starters. So, every assessment methodology for new service implementation processes must be appropriate for different segments of the population. Thirugnanam et al. (2007) specify definition of concept assessment in more detail, claiming that this process means as an analysis of concepts commercial feasibility. Commercial feasibility of possible in the future new service concepts development has to be analysed in terms of their conformity not only to the existing business conditions, but even to be compliant to the prospective future business situations. Such analysis is important enough and responsible. When the results show that some NS concept satisfies the discussed business conditions and future situations, the next logical and systematic question already revolves around the requirement of NS actions planning. According to systematically approach it is obvious that next situational task has to be resolved about certain conditions of service system designing (or designing technology of new service). Whenever NS technology is already designed, it comes term to proceed actions assessing the further NS implementation possibilities, i.e. feasibility of necessary technical actions (electrical, water and sewage installations), also attractiveness to the market, etc. The failing points of existing services can give good new concepts for better services and service maps or blueprints of existing services can be used as guidelines for better new service concepts (Clayton et. al. 2012). It is therefore quite important that agreement between new service participants be reached at this step accurately according to the concept of new service, identifying what customers' needs would be satisfied (Zeithaml et al., 2009).

As mentioned earlier it is sometimes reasonable to omit the step of concept assessment during the implementation process of NS. And differentiation of service concepts by technical-technological complexity is connected with company technical possibilities, and these actions have to be assigned to best internal practical experts. In the absence of the experts it is possible appeal to some outside experts with a request to differentiate concepts. Determined differences of the concepts may depend of staff qualification and also of the type of service activity.

A degree of service customers' satisfaction and probability of successful commercialisation of new service certainly depends on the whole results of concept quality measuring. A good concept after poor implementation at later stages of development can be successful, whereas a bad concept can never be successful even if properly implemented. Therefore, the main focus of the concept formation methodology is on NS concept assessment actions.

\section{Designing the Process Model of New Service Concept Formation}

The first stage of this process always must be to determine the purposefulness of new service implementation in general. It means making a solution about how is necessary to include into the process of new service development. Service company may have many new service ideas, but the purposefulness thereof must be determined in all cases. The current situation of initiating new service development is already examined in detail by many researchers. Determining the purposefulness is relevant for the existing market participants and also for market newcomers. Gava (2008) suggested methodology 
involving comparison of two processes for the determination of purposefulness of any of them. The decision about the purposefulness of new service has to be made as early as possible, whereas it is necessary to prevent unproductive expenditure, when the situation of environment is still inadequate. Appropriate solutions, according to the results of the suggested analysis, can increase the objectivity of subsequent assessment and the probability of successful new services. In this article we will we focus only on the actions of concept drafting.

If the results of investigation show that new service development is basically expedient, the next step is the need for new service concepts formation. If the result is that the new service is not purposeful, the process is terminated. Edvardsson et al. (2005) and Lee et al. (2010) also offer to investigate contemporary research outcomes and they provide ways of a concept elaboration process. Edvardsson et al. (2005) argue that a new service concept helps to express in more detail the service provider's idea of what consumers' problems new service intends to suspend and how it would does. It means that consumers' problems have to be determined exactly and analysed in detail. So, what are the main indications of new service concepts, which can describe their building process?

According Edvardsson et al. (2005) concept description should reflect the attitude of a service enterprise in respect of the some key characteristics of a new service, which feature:

1) Determined main nature of practice;

2) A possible nature of relationships between providers of service and its users; and

3) A grade of problems solved for consumers'.

These characteristics do not oppose the opinion of Patricio et al. (2011) that new service concept shows new value for the customers. Ulrick \& Eppinger (2008) suggest some tools for creating concepts of new products. They mentioned making analogies, stimulating wish and wonders, also using related stimuli, using unrelated stimuli, setting quantitative goals and using the gallery method. They emphasise importance of the stage, which predicts the process analysis of how new service would solve some consumers' problems. Thirugnanam at al. (2007) similarly explained the concept formation process also. We quite agree for their suggestion that in order to recognize the ability of a NS to satisfy consumers' requirements, it is purposeful to select certain quantitative features of new concept as early as it possible even at the step of concept formation and only then foresee the range of their possible values change according to a commercial situation and a business conditions.

According to the systemic approach, the next stage should be towards the selection of the best concept, i.e. the stage of concept assessment. New service concept assessment is the most responsible stage, because its execution largely determines the success of new services.

In accordance with Zeihaml \& Bitner (2003) practical testing of new service concepts is a quite complicated task for any service business because of special features of services. The service implementation processes are comprised of a lot of responsible decisions, and one of the most important and complicated decisions in the all service development processes is identification what services developing would be the most useful, particularly concept selection also, since this influences even the results of developing (Lee et al., 2010).

Idea generation is a relatively inexpensive activity, but real concept formation can be much more expensive. In the development of new tangible products, the concept creation and testing stage involves construction of product prototypes, their forms with drawing pictures and testing for consumer acceptance.

Again, because services are intangible and simultaneously produced, consumed, and frequently concerted, this step presents unique challenges because of difficulties to accomplish them. This stage of service development should involve all persons who have a stake in the new service: customers, employees as well as functional representatives from marketing, operations, and other human resources. As mentioned above, drawing pictures and describing intangible service in concrete terms is quite difficult, particularly when the service is not standardised and may be concreted in real time with customers. Edvardsson et al. (2010) advice that customers cannot experience the real service in isolation from use or consumption, a "pre-service" of some description is necessary required for providing of customers with some main experiences that enable them to evaluate the potential value-in-use of the real service.

For any assessment requires determination of appropriate criteria. Each assessment of new service concepts may be different; it depends on their complexity. Methodology for concepts assessment has to be uncomplicated and understandable for many possible service providers. Poetz and Schreier (2012) suggest that concept formation and assessment actions should confer on experts.

Rahman (2003) suggested methodologies for evaluation suitability of business conditions and presents a model for selection an international market even based on assessment-grouped quantitative criteria, which comprise the sufficiency of market size and the suitability of market structure. Unfortunately, the most of criteria mainly of the mentioned in Rahman's (2003) works are appropriate for assessing opportunities for development activity only in some international markets. And only some criteria are versatile, so some are suitable for evaluating and also screening the best concept in terms of new service feasibility not only for the international market, but for local also and they can be included into the model.

It should be also noted that it is reasonable to reject new service concepts even before the stage of assessing their commercial feasibility if obviously further concepts implementation does not guarantee the achievement of a company objectives, i.e., business future conditions may be determined as unsuitable for implementing some selected concept of new service.

Owens (2007) and Salavou (2004) also approve the necessity of business conditions analysis in the process of new product (or service) development especially from the perspective of all assessed concepts abilities. Mentioned authors in their research state that the probability of commercial success of a new product (or service) increases in the most of cases if such an investigation indicates that a selected concept(s) corresponds to a relevant market requirements. It is quite reasonable to accept the Owens 
(2007) research findings that market analysis is important and even necessary at the most stages of new product (or service) development. Trot (2001) research also confirms the significance of proper market analysis results interpretation for the success of new product. Mentioned position maintains categorical Rahman's (2003) opinion that appropriate option of a market segment even determines the volume of sales and influences a possible profit. Trot (2001) investigated some business situations and determined that existing business analysis results sometimes can show that a new product is quite unmarketable, although after some time it can experience even sensational success. So, according to the same Trot (2001), it is always rational to confirm market accessibility for adoption of a new product.

Very important results according to analysed theme are in the Olsen \& Sallis (2006) research. They have shown that it is not appropriate always to carry out market research according the same level of detail. Olsen \& Sallis (2006) segregate two levels of particularity analysis: "narrow scanning" and "broad scanning" (Olsen \& Sallis, 2006, p. 467). They offered performing narrow scanning (less detailed assessment) in these cases when conceptions of services are created according to ideas which emerge at the initiative of the same service users. Argument of this is that the development of such services is requisite for service consumers. Such an attitude is grounded on the approach that consumer's proposals as to the necessity of a new product (service) eliminate the need to test a NS probability in the market from the perspective of consumers' satisfaction. It is important in this case that market preparedness to adopt a new product (service) is considered sufficient and emphasis is placed on the evaluation of only technical feasibility of a new product (or service). Choice of new service technology has to be determined by a consumer-based approach. Olsen \& Sallis (2006) also mentioned and broad scanning (more detailed assessment), which should cover not only assessment of clients satisfaction, but as well as evaluation of adequacy to always strict ecological requirements, competitiveness also and other environmental determinations.

Poetz \& Schreier (2012) suggest a model for analysis of business conditions, which also is based on expert evaluation. Suggested model as well as is suitable for technical and commercial feasibility assessment of concept development. Poetz \& Schreier (2012) offered also a set of criteria for technical and commercial evaluation of a concept and even a real scale for determining importance (significance) of the mentioned criteria. It is quite useful to accept this differentiation of technical and commercial criteria. But in area of technical assessment is more reasonable and logical to follow Drejer's (2000) approach, which states that assessment of concept's technical feasibility is more purposeful from the perspective of suitability exactly of NS technology. According Longman dictionary technology means "new machines, equipment, and ways of doing things that are based on modern knowledge". Aguileira (2009) suggests characterisation of technology: it is a tool of human, materials and information resources and their conversion into products. So, original in this case Drejer's (2000) suggestion can be substantiated by an undisputed provision that every concept really has even several solutions of technological enforcement, so according to systematically thinking technical assessment is really more reasonable after making a decision about the final concept selection.

Schnetzler's (2005) also suggested some criteria for commercial evaluation of concepts. A questionnaire of 12 simple but significance questions for the concepts evaluation was offered and she states also that received answers will allow identifying the best concept of new product ideas. This methodology with some small improvements is suggested by Drejeris \& Zinkeviciute (2009) study. They offer to select the concepts which would receive more positive answers in according to the mentioned questionnaire. So, the 12 mentioned questions for assessment are (Drejeris \& Zinkeviciute, 2009):

1. Do the NS concepts under analysis reflect some clients' needs, or special requests?

2. Are clients' requests adequately expressed in the technical and commercial characteristics of NS concepts?

3. * Do NS concepts consider some problems of any existing service?

4. Is the NS concept more advantageous compared with suggested by existing competitors?

5. * Is the concepts of NS environment more clientsfavourable compared to the existing services or provided by competitors?

6. Does the concept according to NS foresee some possibilities to meet some other future market requirements?

7. Is the NS based on the new concept more accessible to clients and also providers?

8. Can the service according to a new concept improve any actions of the existing service?

9. * Are the concepts of new service more attractive than existing services to any current and prospective clients?

10. * Is a new service implementation according to the concept in line with the all requirements of external environment?

11. * Are technical also organisational possibilities real for implementation of a new service according to the new concepts?

12. * Is the providing of new service dangerous for customers and employees of service company?

But use of the questionnaire is really acceptable in terms of its substance and importance (significance), but it would be systematically purposeful to add some commercial questions (criteria) relating to the external environment of the company. It is also reasonable to support Poetz \& Schreier (2012) opinion for concept evaluation using the experts' method. Also, their methodology uses almost the same indicators in the accepted set of criteria as proposed earlier. Lee et al. (2010) suggested 21 criteria, which are divided into 5 groups: strategy, technology, market, implementation, operation. The division of the criteria into groups should be welcomed; some of those omitted in the our mentioned list are obviously important (Lee et al., 2010). Questions "Does the NS development meet the company's strategic goals" and "Does expected potential growth of the market after implementing NS" are particularly important for every business company and can be accepted. But not all of the criteria may reflect the quality of NS concepts in the list offered by Lee et al. (2010). As each NS concept may have several technological 
solutions, what is the purpose of assessing the concept from the technological point of view? Parida and Chattopadhyay (2207) suggested multi-criteria methodology for new service technology assessment. The operation criteria mentioned by Lee et al. (2010) are more purposeful to include into the set of NS technology assessment criteria.

Therefore, mentioned earlier Rahman (2003) in his model aimed at selecting more specific criteria for assessing concepts of products for international market. It should be pointed out that other authors have no objection distribution of criteria. So, it is purposeful to add mentioned set of 12 criteria by another mentioned by other authors:

* Do any real possibilities exist for a proper handling of environmental, disposal and other environmental problems after implementing NS according to the concepts?

* Are the processes taken according to new service concepts not in conflict with occupational safety requirements?

Will new service according to the concepts improve reputation, image of the service company?

Do the NS concepts encourage the use of technicaltechnological progress?

* Do the NS concepts development meet the company's strategic goals?

Is potential growth of the market expected after implementing the NS according to the new concepts?

In total we found 18 criteria (questions) for NS concept assessment, which would be divided into 3 groups: 1) Company requirements, 2) Satisfaction of clients' requirements, 3) Implementation options.

But usually, the simple summing of positive answers will not produce objective results of assessment because of different importance (significance) of the questions. So, it is need to give some value of importance for every criterion or for groups of criteria. Then the importance of each group of criteria for results and process of new service development should be discussed. And in order to increase objectivity of assessment also requires providing a quantitative expression.

When a company already has a real NS concept, which is intended to be developed, the next step is to create a plan for its implementation and a system for NS delivering. The service system incorporates "the resources available to the process for realizing the service concept" (Edvardsson et al. 2005). Smith et al. (2007) identify a range of resources that are encompassed within the service system. They include:

1) human resources (skills and knowledge, staff needs and views on new services);

2) customers (understanding their wishes and expectations, identifying appropriate levels of customer knowledge, effectively designing customer interfaces (their telephone, automated conversation or face to face);

3) physical/technical (buildings, location and communication systems);

4) organisation and control (structures and hierarchies, supply chain processes and customer relationship management).

Magio et al. (2009) define a service system as a dynamic configuration of value-cocreation, including resources, people, organisations, shared information (language, laws, measures, methods), all connected internally and externally propositions of other service systems. It is important that Thirugnanam (2007) agrees in general that service system has to be designed on the basis of selected new service conception.

Thus, according to the presented arguments, the real model of new service concept(s) formation is prepared (figure 1). The proposed model is flexible in construction, as it provides steps for different potential solutions that are dependent on the business situation and are also influenced by environmental conditions analysis results. And it is appropriate even to accept Sujin Choi's (2011) findings that the proper use of the market analysis results, execution of well-planned and coordinated actions allows newcomers to penetrate the market and successfully develop the service business.

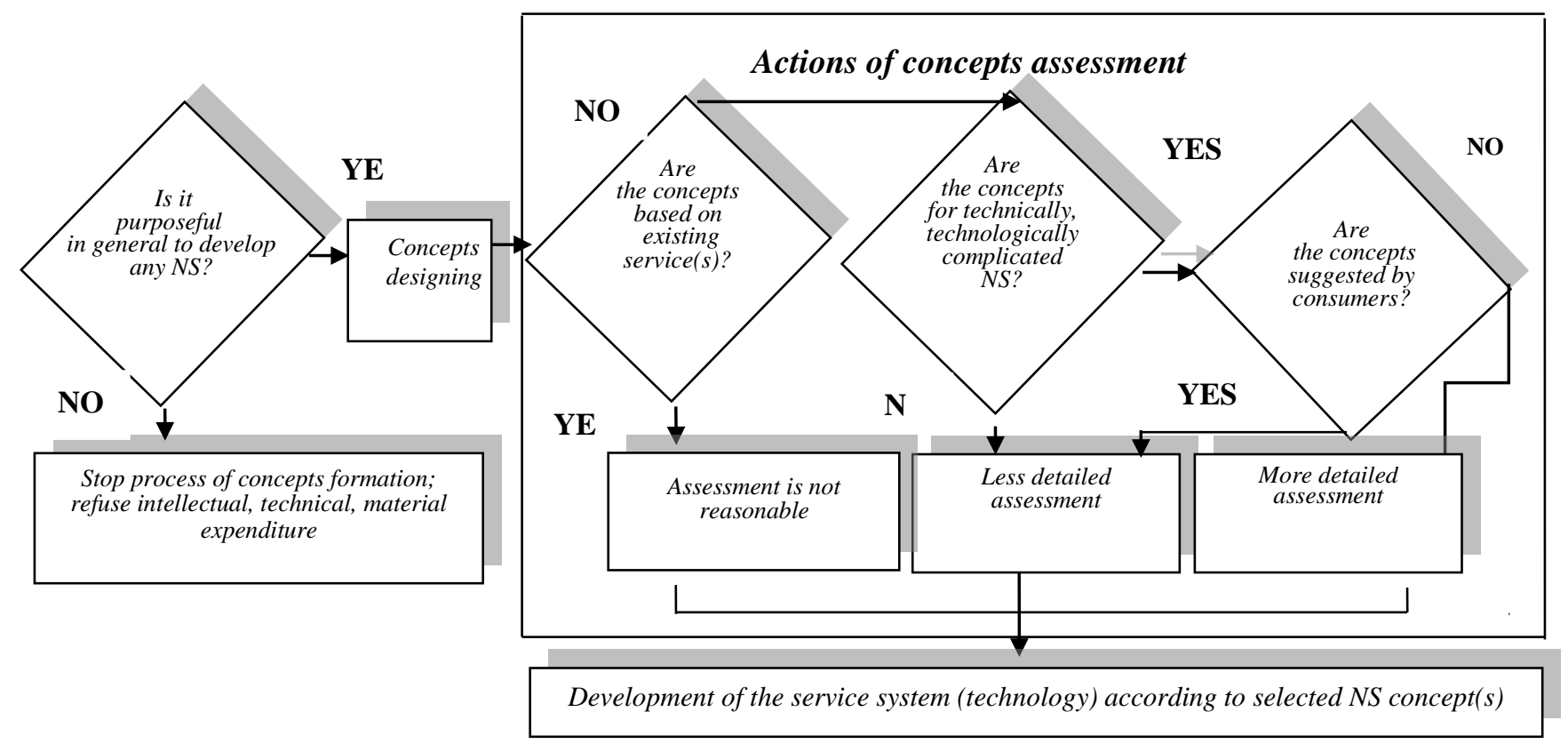

Figure 1. Model of New Service Concept(s) Formation. Source: developed by autors 
In general, it can be noted that the created service system even has to be used as an approach to reach sustainability of company activity (Manzini et al., 2001) or new health service may be embedded within new health care philosophies (Smith et al., 2007).

The following sections of the paper discuss the components of the proposed model with explanation of its using and continued focus on the concept assessment stage. In order to test the model, a survey of medicines buyers in 12 pharmacies was carried out.

\section{Determining the Purposefulness of New Service Development}

The purposefulness of NS development can be determined with a focus on parallel consideration of the purposefulness to develop two possible alternatives of service business: creation and implementation of NS or increasing volume of existing services through application of service sales promotion tools. Such methodology would help to answer the question: whether it is worth for the company to engage into the process of NS development in general.

So, the first step, i.e. the determination of the purposefulness of a new service is necessary, although it is often missed by some other authors. Such methodology should be based on assessing the consumers' need for existing services and assessment of company's capacity to develop new ones. Even financial potential is important in this case.

Processes of the purposefulness assessment in the scheme of new service development must have a cyclical form. It indicates that the consumer needs have to be regularly tested in order to grasp a thread showing a decrease in consumers' satisfaction and start considering introduction of a new service (or modification of those already provided earlier).

The determination of the purposefulness of health care services and the results of the analysis were fully proved and demonstrated suitability of this stage of the model for real business conditions. Implementation of the eprescriptions project would be in compliance with current policies of the Ministry of Health. Therefore, the next step is NS concept design.

\section{New Service Concepts Designing}

In some cases, designing of a new service concept may not be different with ideas creating processes when they determine the mentioned date, which form can depend not only on the nature of services, but also on the companies' creative possibilities. In addition it is offered that the first of the mentioned characteristics is the nature of activity and it can be also incorporated even in the description of a new service idea.

Then during the designing NS concepts, next can be reasonable action is finding solutions for the relationships between consumers and service providers. And existing services also can be delivered in different ways, e.g. even small improvements in service providing with high visibility can modify customers' experiences and challenge changing of some service concept.
Thus, the concepts of services, which are already known for the consumers and are really recognised as eligible for some customer segment, do not require a very detailed assessment.

As emphasised by Edvardsson et al. (2005), a degree of consumer problem solving may be regarded as an element of NS concept creation. We find it similar (or even identical) to the degree of customer satisfaction which can be regarded as a criterion for NS concept assessment.

They suggest methodology where under a problem has to be divided into subproblems using a classification tree and a real example of methodology for new concept generation is presented.

Summarized the information, can be stated that the general process of NS concept designing consist of these main parts:

1) determination the nature of service activities (this characterization might also be in the content of new service ideas); and

2) more detailed specification of a NS idea traits by identifying though several qualitative or quantitative characteristics of some specific NS procedures.

With regard to concept creation for new services, in some cases can really be reasonable to use promotion of some internal or external skilled experts, who can help in process of decision making by interpretation of a market needs assessments results, also for identifying the required above-mentioned new service characteristics. In this case external experts asking means invitation business consultancy companies, which are capable performing of such listed actions.

As mentioned above, at the stage of concept formation for new services, implementers need to find as many as possible different adjusted expressions of the selected idea. Ideas can be concretised by several characteristics listed above. The higher is the number of appreciated objects (alternatives) the more objective is the decision.

For the implementation of the mentioned eprescriptions project, few concepts were created suggested by customers. They differed by the quantity of information about pharmacies customers and by possibilities to access the system.

\section{New Service Concept(S) Assessment}

As it is mentioned above, every idea can be expressed by several concepts, but their further development may be uneven. So the purpose of such assessment is to ascertain which one (or more) concept(s) can be the best for a company under the current or future conditions in the analysed market. Accordingly, when NS concepts are built the next frequent step is concepts assessment.

Objective assessment and selection of the best NS concept is an important and responsible process for proper services system designing. So, the main goal of this chapter is to determine which criteria must be included

into the set of assessment instruments and to find the best way for the most objective solution.

As mentioned above in order to impart a quantitative form for the mentioned assessments, it is purposeful to apply indexes of importance (weight) $\boldsymbol{\eta}$ for every mentioned 
criterion (or for groups of criteria) and to calculate according to the results of survey in the following way:

$$
P_{i}=\sum_{j=1}^{18} K_{i j} \eta_{j}
$$

Where: $P_{i}-$ total value of concept $i ; K_{i j}-$ the value of concept $i$ assessment according to criterion $j ; \eta_{j}-$ the importance (significance) of criterion $j ; 18-$ the number of criteria.

The values of cumulative criterion $T_{i}$ allows ranking of the concepts. Such assessment based on the results of customers and employees' survey will help to make the most objective decision.

For determination the relative importance (significance) of the criteria the best and the simplest method is experts' method. Experts' method is not the most objective method. Therefore, in order to increase objectivity, it is appropriate to use quantitative calculations.

Taking into account the specifics of the evaluation, in particular the importance of consumer services, it is purposeful to include consumers into the experts' groups.

Further assessment should be:

$$
W_{j}=\sum_{u=1}^{m} W_{j u} ; j=1, \bar{k}
$$

Where: $W_{j}$ - the sum of all expert estimates according to all criteria; $j$-th criterion $u$ expert's estimation; $m$ - the number of experts.

The relative importance (significance) $\boldsymbol{\eta}^{\text {of }}$ the criteria determined by the formula (3):

$$
\eta_{j}=\frac{W_{j}}{\sum_{j=1}^{k} W_{j}} ; j=1, k,
$$

The concept given the maximum quantity of points is considered to be the best.

It should be noted that the comparison of results is right only if concepts were evaluated by using the same criteria. It means that concepts which were assessed by less detailed assessment scheme can be compared only with each other; the same situation is with concepts which are assessed by more detailed assessment scheme.
Assessment results will be more precise if all the concepts are assessed using more detailed assessment scheme. If only concepts which satisfy at least one of the conditions (concept is based on existing service(s), it is not for technically, technologically complicated NS or it is suggested by customers) have to be compared, they can be assessed using less detailed assessment scheme.

However, according to the above mentioned authors, concepts assessments still have to focus on the consumers needs. Therefore, it is appropriate to assess 12 criteria offered by Schnetzler (2005) and Drejeris \& Zinkeviciute (2009), group them (satisfaction of customers' requirements, implementation options, company requirements) and supplement with the criteria proposed by earlier mentioned Lee et al. (2010) and the suggested by other authors.

So, NS concepts could be assessed by a total 18 criteria Most of the criteria have to be from the "customers' satisfaction" group. All criteria are formulated in a form of questions. But how to compare concepts of different groups which are assessed using less and more detailed assessment schemes? This question can be answered by experts who have to determine the different relative weightings and, thus, different their importance (significance).

It should be noted that the evaluation of a new service concepts, as suggested by Drejeris \& Zinkeviciute (2009) and modified by the authors of this paper, essentially satisfies the needs for broad scanning (more detailed assessment), mentioned by Olsen \& Sallis (2006). By the way, it is quite possible to choose some necessary criteria for less detailed assessment from the list of supposed criteria. So, needful criteria of less detailed assessment really have to correlate with evaluations of technical possibilities for NS concept development. Therefore, it is purposeful to create a new set of some criteria $(3,5,7,8$, $11,13,14$, and 17 from earlier mentioned list) and purposeful to apply them to less detailed assessment of the concepts.

So, according to suggested methodology if any concept does not satisfy at least one criteria of the less detailed assessment, its further selecting really can be suspended and such concept has to be eliminated as quite inappropriate. Results of the concept assessment are presented in an appropriate form in table 1.

\begin{tabular}{|c|c|c|c|c|c|c|c|c|}
\hline Criteria & $j_{1}$ & & $j_{2}$ & & $j_{j}$ & & $\sum^{18} K_{i j} \eta_{j}$ & Ranking \\
\hline Concepts & $\begin{array}{l}\text { Relative } \\
\text { importance } \eta_{1}\end{array}$ & $K_{i j} \eta_{j}$ & $\begin{array}{l}\text { Relative } \\
\text { importance } \boldsymbol{\eta}_{2}\end{array}$ & $K_{i j} \eta$ & $\begin{array}{l}\text { Relative importance } \\
\eta_{j}\end{array}$ & $K_{e j} \eta$ & & \\
\hline$i_{1}$ & $\begin{array}{l}\text { Value of concept } \\
i_{1} \text { according to } \\
\text { criterion } j_{l}\end{array}$ & & $\begin{array}{l}\text { Value of concept } \\
i_{1} \text { according to } \\
\text { criterion } j_{2}\end{array}$ & & $\begin{array}{l}\text { Value of concept } \\
i_{1} \text { according to } \\
\text { criterion } j_{j}\end{array}$ & & $\begin{array}{l}\text { Total value of } \\
\text { concept } \boldsymbol{i}_{1}\end{array}$ & \\
\hline$i_{2}$ & $\begin{array}{l}\text { Value of concept } \\
i_{2} \text { according to } \\
\text { criterion } j_{1}\end{array}$ & & $\begin{array}{l}\text { Value of concept } \\
i_{2} \text { according to } \\
\text { criterion } j_{2}\end{array}$ & & $\begin{array}{l}\text { Value of concept } \\
i_{2} \text { according to } \\
\text { criterion } j_{j}\end{array}$ & & $\begin{array}{l}\text { Total value of } \\
\text { concept } \boldsymbol{i}_{2}\end{array}$ & \\
\hline$i_{n}$ & $\begin{array}{l}\text { Value of concept } \\
i_{n} \text { according to } \\
\text { criterion } j_{l}\end{array}$ & & $\begin{array}{l}\text { Value of concept } \\
i_{n} \text { according to } \\
\text { criterion } j_{2}\end{array}$ & & $\begin{array}{l}\text { Value of concept } \\
i_{n} \text { according to } \\
\text { criterion } j_{j}\end{array}$ & & $\begin{array}{l}\text { Total value of } \\
\text { concept } \boldsymbol{i}_{n}\end{array}$ & \\
\hline
\end{tabular}

Table 1

Results of Concepts Assessment 
Using the proposed methodology for assessment allows ranking of all NS concepts and facilitates finding the best quantitative solution, which would be the most objective in current business situation.

During the assessment of concepts for the eprescriptions project, it was determined that each of the concepts is for technically and technologically

complicated NS, but all of them are suggested by consumers. According to the suggested model, it means that less detailed assessment is sufficient.

And according to the selected conception, it is purposeful to work further towards a new service system design.

\section{Service System Design}

A lot of scientific works highlight that one of the most important condition for a successful NS implementation and further provision is a designing of appropriative service system (or reasoned technology for new service providing)..

Therefore, it can be stated that planning of a new service system encompasses determination procedures, processes and other elements, and conformation of their sequence.

Designing a service system was the most difficult task in the e-prescriptions project because of potentially low use of IT skills by physicians, who were determined as the main participants of the service system. The new service technology involves the following actions: physicians record the patient's diagnosis and the medicines in the information system; this information reaches any pharmacy; the patient can receive the necessary medicines after showing his/her personal identification documents to the pharmacist. Suitability of the actions suggested in the model is fully proven and the results showed that the model is available for use under realistic conditions. Currently, the e-prescriptions project is under implementation in Lithuania.

\section{Conclusions}

Comprehensive studies have showed that the investigators attitudes about the soundness of new service concepts designing and their evaluation are quite contradictory. Furthermore, service activity has not appropriate methodology for concepts formation and assessment that would be applied directly to the service activity.

The reasonability of forming a new service concept has been validated and the model for appropriate concepts designing has been suggested. Submitted model consists of the following main components: determining NS purposefulness, concepts designing, concepts assessment according to two separated sets of criteria (for less detailed assessment and for more detailed assessment), and service system designing.

Criteria for concept assessment were determined and they grouped for narrow scanning and broad scanning. Situations were identified when concept assessment is not reasonable.

Presented methodology offers differentiating concepts according to the technical-technological complexity of possible new service and even the sources of ideas. The suggested methodology also makes it possible in determined situations to skip some stages of assessments. Such situations are connected with concept assessments, proposed by clients.

Use of suggested methodology allows reducing assessment cost and reducing the time needed for evaluating. It is appropriate and beneficial to use for service companies seeking to implement new services.

The practical suitability of the suggested model was proved in the implementation of the e-prescriptions projects, i.e. the model was found useful when applied in real business situations.

Testing of the model took too much time, as the survey of pharmacies was carried out in form of verbal interviews. In the future, it would be reasonable to carry out consumer surveys online to shorten survey time and reduce other costs. The suggested model will be also tested in other service sectors in the future.

\section{References}

Aguileira, J. M. (2009). Why Food Microstructure? Journal of Food Engineering, 67(1), 3-11.

Battor, M. \& Battor. M. (2010). The impact of customer relationship management capability on innovation and performance advantages: testing a mediated model. Journal of Marketing Management, 26(9-10), 842-857. https://doi.org/10.1080/02672570903498843

Chenet, P., Dagger, T., \& O'Sullivan, D. (2010). Service Quality, Trust, Commitment and Service Differentiation in Business Relationships. Journal of Services Marketing, 24(5), 336-346. https://doi.org/10.1108/08876 041011060440

Clayton, R. J., Backhouse, C. J. \& Dani, S. (2012). Evaluating existing approaches to product-service system design: a comparison with industrial practice. Journal of Manufacturing Technology Management, 23(3), $272-298$. https://doi.org/10.1108/17410381211217371

Drejer, A. (2000). Integrating Product and Technology Development. European Journal of Innovation Management, 3(3), 125-136. https://doi.org/10.1108/14601060010334885 
Egle Drejeriene, Rolandas Drejeris. Systematic Approach to A New Service Ideas Conceptualisation: Quantitative...

Drejeris, R., Zinkeviciute, V. (2009). Modelling of a new service concept development process. Current Issues of Business and Law, 4, 22-36

Edvardsson, B., Enquist, B. \& Johnston, R. (2010). Design Dimensions of Experience Rooms for Service Test Drives: Case Studies in Several Service Contexts. Managing Service Quality, 20(4), 312-327. https://doi.org/10. $1108 / 09604521011057469$

Edvardsson, B. \& Gustafsson, I. \& Roos, G. (2005). Service Portrays and Service Constructions - a Critical Review through the Lens of the Customers. International Journal of Service Industry Management, 1(16), 107-121. https://doi.org/10.1108/09564230510587177

Gava, G. (2008). The Purposefulness in our Thought: A Kantian Aid to Understanding Some Essential Features of Peirce, Transactions of the Charles S. Peirce Society. A Quarterly Journal in American Philosophy, 44(4), 699-727.

Gomes, C. F., Yasin, M. \& Lisboa, J. (2007). The Effectiveness of Hospitality Service Operations: Measurement and Implementation Concerns. International Journal of Contemporary Hospitality Management, 19(7), $560-573$. https://doi.org/10.1108/09596110710818301

He, Q., Ghobadian, A., Gallear, D., Beh L-S., \& O'Regan, N. (2015). Towards Conceptualising Reverse Service Supply Chains. Supply Chain Management: An International Journal, 21(2), 166-179.

Konu, H., Tuohino, A. \& Komppula, R. (2010). Lake Wellness-a Practical Example of a New Service Development (NSD) Concept in Tourism Industries. Journal of Vacation Marketing 16(2), 125-139. https://doi.org/10. $1177 / 1356766709357489$

Henrich, A., Wikstrom, A., \& Jackson, M. (2012). Reflective Practice in Design Thinking, Learning and Performing Product and Process Development. DS 71: Proceedings of NordDesign, the 9th NordDesign conference, Aarlborg University, Denmark. 22-24.08.2012.

Lee, H., Kim, C. \& Park, Y. (2010). Evaluation and Management of New Service Concepts: An ANP-based Portfolio Approach. Computers \& Industrial Engineering, 58, 535-543. https://doi.org/10.1016/j.cie.2009.11.016

Maglio, P.P., Vargo, S. L., Caswell, N. \& Spohrer, J. (2009). The Service System is the Basic Abstraction of Service Science. Information Systems and e-Business Management, 7, 395-406. https://doi.org/10.1007/s10257-008-0105-1

Manzini, E. (2002). Context-based Wellbeing and the Concept of Regenerative Solution: a Conceptual Framework for Scenario Building and Sustainable Solutions Development. The Journal of Sustainable Product Design, 2(3/4), 141-148. https://doi.org/10.1023/B:JSPD.0000031026.11908.1d

Olsen, N. \& Sallis, J. (2006). Market Scanning for New Service Development. European Journal of Marketing, 40(5/6), 466-484. https://doi.org/10.1108/03090560610657796

Owens, J. D. (2007). Why do some UK SMEs still find the implementation of a new product development process problematical? Management Decision, 45(2), 235-251. https://doi.org/10.1108/00251740710727269

Parida, A. \& Chattopadhyay, G. (2007). Methodology and theory: development of a multi-criteria hierarchical framework for maintenance performance measurement (MPM). Journal of Quality in Maintenance Engineering, 13(3), 241258. https://doi.org/10.1108/13552510710780276

Patricio, L., Fisk, R. P., Cunha, J. F. \& Constantine, L. (2011). Multilevel Service Design: From Customer Value Constellation to Service Experience Blueprinting. Journal of Service Research, March, 3-25. https://doi.org/10. 1177/1094670511401901

Poetz, M. K. \& Schreier, M. (2012). The Value of Crowdsourcing: Can Users Really Compete with Professionals in Generating New Product Ideas. Journal of Product Innovation Management, 29(2), 245-256. https://doi.org/10. 1111/j.1540-5885.2011.00893.x

Rahman, S. H. (2003). Modeling of International Market Selection Process: a Qualitative Study of Successful Australian International Business. Qualitative Market Research: an International Journal, 6(2), 119-132.

Salavou, H. (2004). The Concept of Innovativeness: Should We Need to Focus?, European Journal of Innovation Management, 7(1), 33-44. https://doi.org/10.1108/14601060410515628

Schnetzler, N. (2005). The Idea Machine. How Ideas Can Be Produced Industrially, Wiley-VCH Verlag: Weinheim.

Smith, A, M., Fischbacher, M., \& Wilson, F. A. (2007). New Service Development: From Panoramas to Precision. European Management Journal, 25(5), 370-383. https://doi.org/10.1016/j.emj.2007.06.007

Sujin Choi. (2011). Facilities to Service Based Competition, not Service to Facilities Based, For Broadband Penetration: a Comparative Study between the United States and South Korea. Telecommunications Policy, 35(9/10), 804-817. 
https://doi.org/10.1016/j.telpol.2011.08.003

Thirugnanam, S., Vinodh, S., Devadasan, R. (2007). Innovative quality circle: a technique for coupling innovation and quality through employee participation. International Journal of Services and Operations Management, 3(4), 478495. https://doi.org/10.1504/IJSOM.2007.013467

Tidd, J. \& Bodley, K. (2002). The Influence of Project Novelty on the New Product Development Process, R\&D Management, 32(2), 127-137. https://doi.org/10.1111/1467-9310.00245

Trot, P. (2001). The Role of Market Research in the Development of Discontinuous New Products. European Journal of Innovation Management, 4(3), 117-125. https://doi.org/10.1108/14601060110390585

Ulrich, K. T. \& Eppinger, S. D (2008). Product design and development, McGraw-Hill: Boston.

Wood, A. (2003). Managing Employees' Ideas. rom Where do Ideas Come?, The Journal for Quality \& Participation, 26(2), 22-26.

Zeithaml, V, A. \& Bitner, M, J. (2003). Service Marketing: Integrating Customer Focus across the Firm, McGraw-Hill Higher Education: New York.

Zeithaml, V. A., Bitner, M. J. \& Gremler, D. D. (2009). Services Marketing: Integrating Customer Focus Across the Firm, Mc Graw - Hill: Irwin, Boston, Burr Ridge, Toronto.

Zomerdijk, L. \& Voss, C. (2011). NSD Processes and Practices in Experiential Services. Journal of Product Innovation Management, 28(1), 63-80. https://doi.org/10.1111/j.1540-5885.2010.00781.x

The article has been reviewed.

Received in April, 2016; accepted in June, 2017. 